\title{
Autoritarismo e guerra às drogas: violência do racismo estrutural e religioso
}

\author{
Andréa Pires Rocha ${ }^{1}$ \\ https://orcid.org/0000-0003-4158-7541
}

Rita de Cássia Cavalcante Lima ${ }^{2}$

https://orcid.org/0000-0001-9918-7503

\author{
Daniela Ferrugem ${ }^{3}$ \\ https://orcid.org/0000-0002-2861-1191
}

\author{
${ }^{1}$ Universidade Estadual de Londrina, Departamento de Serviço Social, Programa de Pós-Graduação em Serviço Social e \\ Políticas Sociais, Londrina, PR, Brasil \\ ${ }^{2}$ Universidade Federal do Rio de Janeiro, Programa de Pós-Graduação em Serviço Social, Rio de Janeiro, RJ, Brasil \\ ${ }^{3}$ Universidade Federal do Rio Grande do Sul, Instituto de Psicologia, Porto Alegre, RS, Brasil
}

\begin{abstract}
Autoritarismo e guerra às drogas: violência do racismo estrutural e religioso
Resumo: Este artigo toma as políticas de drogas como mirante de análise sobre a racionalidade governamental que incrementa respostas autoritárias à crise do capital. Esta resposta em período de neoliberalismo e de neoconservadorismo é seletiva e requisita apreender dois componentes do racismo estrutural - o racismo institucional e o religioso que se atualizam na política de drogas. A destituição da Presidenta Dilma Rousseff indicou uma crise geral de autoridade que fortaleceu a ascensão neopentecostal na organização das massas populares no Brasil a favor de um projeto necroeconômico e necropolítico abertamente antidemocrático. Com autores críticos, recupera-se a disputa materializada com o uso da força punitiva do Estado e com a atuação fundamentalista de segmentos neopentecostais. Apontamos que no interior do Estado neoliberal de cunho penal, o conservadorismo, racismo e ódio de classe recrudescem mecanismos de controle justificado pela guerra às drogas, incidindo sobre os corpos e qualquer vestígio de vida de negros e pobres.
\end{abstract}

Palavras-chave: Autoritarismo. Neoliberalismo. Proibicionismo às Drogas. Racismo. Neopentecostalismo.

\section{Authoritarianism and war on drugs: the violence of structural and religious racism}

Abstract: This article gets drug policies as an analysis point on governmental rationality that reinforces authoritarian responses to the capital crisis. This response in a period of neoliberalism and neoconservatism is selective and requires to apprehend two components of structural racism - institutional and religious racism that are updated in drug policy. The President Dilma Rousseff's impeachment indicated a general crisis of authority that strengthened the neo-Pentecostal rise in the organization of the popular masses in Brazil in favor of an openly anti-democratic necro economic and necropolitical project. With critical authors, the materialized dispute is retrieved with the use of the punitive force of the State and with the fundamentalist action of neo-Pentecostal segments. We point out that within the neoliberal penal State, conservatism, racism and class hatred reinforce control mechanisms justified by the war on drugs, focusing on the bodies and any trace of life of blacks and the poor people. Keywords: Authoritarianism. Neoliberalism. Prohibition of Drugs. Racism. Neopentecostalism.

Recebido em 30.06.2020. Aprovado em 05.08.2020. Revisado em 05.10.2020.

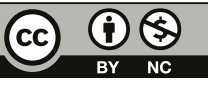

Este é um artigo publicado em acesso aberto (Open Access) sob a licença Creative Commons Attribution NonCommercial, que permite uso, distribuição e reprodução em qualquer meio, sem restrições desde que sem fins comerciais e que o trabalho original seja corretamente citado. 


\section{Introdução}

O Estado burguês é autoritário e penal, características que o acompanham em suas diferentes fases, adequando-se às necessidades objetivas de cada momento histórico em nome da manutenção do modo de produção capitalista. O autoritarismo é justificado pela ideologia dominante que, como Marx e Engels (2016) enfatizam, sustentam as relações estruturais deste Estado, centradas na exploração da força de trabalho e na manutenção da propriedade privada. Essa ideologia, por sua vez, tem sua concreticidade materializada no bojo das relações superestruturais estabelecidas nas esferas da política e do direito, que retroalimentam a lógica do capital. Conquanto, a forma mais visível se mostra pela violência ideologicamente ancorada e naturalizada quando extrapola os limites do controle de mentes, conduzindo-se ao controle de corpos, em especial de negros e pobres.

$\mathrm{Na}$ arena da luta de classes, o autoritarismo do Estado burguês nunca cessou. Em tempos de paz, empreende guerras que, historicamente carregam a hierarquização das vidas a partir da criação das raças, antes como conceito biológico, hoje como uma categoria analítica. Racismo que sempre se estruturou como forma de eleger os inimigos para guerras de dominação, controle e exploração. $\mathrm{O}$ autoritarismo brasileiro tem o racismo e sistema escravocrata como seus primeiros expoentes e, segundo Schwarcz (2019), sempre esteve presente na história do país, materializando-se no mandonismo dos senhores de engenho e, posteriormente, no delineamento da república sob a égide do patrimonialismo estatal que tem a corrupção como uma de suas principais expressões contemporâneas. Além disso, é essencial lembrarmos que foram inúmeros os contextos cuja frágil democracia brasileira foi atacada frontalmente, dos quais destacamos Ditadura Vargas, Ditadura militar e a ascensão conservadora do governo de Jair Messias Bolsonaro. Os impactos atuais do autoritarismo no Brasil estão na ofensiva neoliberal, no racismo estrutural, na desigualdade social, na violência e suas múltiplas expressões e no recrudescimento da intolerância e do discurso de ódio voltando contra os direitos humanos e a diversidade.

Para este artigo optamos por explorar dois componentes do racismo estrutural, entendido como elemento delineador das relações sociais brasileiras, que nos parecem ser relevantes para a aproximação ao substrato beligerante da política de drogas. Trata-se, primeiramente, do racismo institucional perpetrado pela violência do Estado cunhados em um Sistema Penal racista, seletivo (ZAFFARONI, 2014; BARATTA, BISSOLI FILHO, 2019) e justificado por legislações proibicionistas ancoradas pela guerra às drogas. Em um segundo momento, do racismo estrutural particularizado no chamado racismo religioso praticado por grupos fundamentalistas de cariz neopentecostal, cujo segmento persegue as religiões de matriz africana e tem disseminado valores conservadores e de extrema direita, inclusive, alçando maior número de representantes eleitos em 2018, seja para o Parlamento ou para o Executivo (CUNHA, 2019; VIEIRA, 2018). Fenômeno que, segundo Maxx (2020), trata-se da semitização do neopentecostalismo que reúne uma "conexão contraditória entre o judaísmo baseado na lei e na disciplina e o cristianismo que oferece o perdão", gerando, a partir da intolerância religiosa, a expulsão de praticantes de religiões de matriz africana de domínios territoriais.

A escolha desse debate se deve ao reconhecimento da produção crítica já existente sobre o proibicionismo às drogas, substrato das políticas de drogas no mundo que, no caso brasileiro, já explorou algumas mediações, como a influência das díades médico-legal e a da geoeconomia e geopolítica (RODRIGUES, 2004; LIMA, 2009; DELMANTO, 2010). Porém, um exame mais detido da realidade conforma a hipótese de que outras mediações relativas ao racismo precisam ser desveladas em sua relação com a política de drogas, reconhecendo a relevância da expansão evangélica no País, a partir de 1980, particularmente, os neopentecostais (MARIANO, 2014), além da força política que associações de comunidades terapêuticas religiosas ganharam para disputar a direção da política de drogas e os recursos públicos (IPEA, 2017; VASCONCELOS; CAVALCANTE, 2019). Questionamos, então, o que o giro recente e regressivo da política de drogas revela de uma crise geral de autoridade no Brasil?

O mirante de análise reúne autores críticos da tradição marxista, sendo alguns clássicos, como Karl Marx, Friedrich Engels e Antônio Gramsci, e outros contemporâneos, como Pierre Dardot e Christian Laval. Para cotejar a questão norteadora, outras abordagens críticas precisaram ser acionadas, reconhecendo-se o necessário diálogo plural e suas diferenças internas. Assim, da sociologia das religiões, selecionamos os trabalhos de Ricardo Mariano e Magali do Nascimento Cunha, com ampla e sistemática pesquisa sobre o 
crescimento neopentecostal no Brasil; da criminologia crítica, Eugenio Raúl Zaffaroni, Alessandro Baratta Ana Cristina Pinheiro Flauzina; do racismo estrutural, especialmente a partir de Sílvio Almeida e Angela Davis.

\section{Algumas aproximações marxistas acerca do autoritarismo}

Gramsci, ao desenvolver reflexões sobre o fascismo ${ }^{1}$ - sentido em seu corpo -, problematiza a questão da autoridade, num primeiro momento, a toma como trava da mudança histórica, o elemento coercitivo que se interpõe à liberdade humana; daí, a afirmação de que "a história é liberdade enquanto é luta entre liberdade e autoridade, entre revolução e conservação, luta na qual a liberdade e a revolução continuamente prevalecem sobre a autoridade e a conservação" (GRAMSCI, 1999, p. 300). Porém, o pensador não era um idealista e considerou ser funcional a autoridade e a hegemonia, enquanto dois momentos. Aquela não seria apenas o elemento opositor ao desenvolvimento da liberdade, mas necessária se a "origem for 'democrática', ou seja, se a autoridade for uma função técnica especializada e não um 'arbítrio' ou uma imposição extrínseca e exterior, a disciplina é um elemento necessário de ordem democrática, de liberdade" (GRAMSCI, 2007, p. 67).

Esse debate advinha da crise de autoridade identificada pelo autor na perda do reconhecimento da liderança de partidos tradicionais pelas frações de classe que as representava em um contexto de crise econômica e instabilidade de poder da burguesia para manter as rédeas do acúmulo de capital sob a moldura da democracia, mesmo que fosse na esfera formal. Gramsci $(2007$, p. 60) alerta que

Quando se verificam estas crises, a situação imediata torna-se delicada e perigosa, pois abre-se o campo às soluções de força, à atividade de potências ocultas representadas pelos homens providenciais ou carismáticos '[...] O processo é diferente em cada país, embora o conteúdo seja o mesmo' [...] Fala-se de 'crise de autoridade': e isso é precisamente a crise de hegemonia, ou crise do Estado em seu conjunto. A crise cria situações imediatas perigosas, já que os diversos estratos da população não possuem a mesma capacidade de se orientar rapidamente e de se reorganizar com o mesmo ritmo.

Tratava-se, portanto, de uma crise de hegemonia da classe dirigente no âmbito da crise orgânica geral do Estado liberal italiano, após a Primeira Guerra Mundial, quando a decomposição do parlamentarismo foi uma das expressões. Para o mesmo período histórico, Dardot e Laval (2016, p. 57) aprofundam as mediações para se apreender a natureza da crise.

A Primeira Guerra Mundial e as crises que vieram depois dela apenas aceleraram uma revisão geral dos dogmas liberais do século XIX. As repetidas crises econômicas, os fenômenos especulativos e as desordens sociais e políticas revelavam a fragilização das democracias liberais. O período de crises múltiplas gerava uma ampla desconfiança em relação à uma doutrina econômica que pregava liberdade total aos atores no mercado.

As funções do Estado burguês vão se reconfigurando, forjando uma agenda capaz de intervir política à orientação econômica e social exigida, num primeiro momento, pelo liberalismo e, a partir da crise de 1970, pelo neoliberalismo. Destarte, trata-se de formas de responder à crise do governo liberal, de superação das dificuldades inerentes ao capitalismo. Mas liberalismo ou neoliberalismo, o que há de comum entre ambas as correntes é o totalitarismo, ou seja, a "destruição da sociedade liberal" e a produção de uma nova racionalidade governamental, na qual caiba ao "Estado o papel essencial de assegurar a cada indivíduo os meios de realizar seu próprio projeto" (DARDOT; LAVAL, 2016, p. 61).

Para Gramsci (2007), a entrada direta das massas na esfera política tornou o processo paradoxal e a saída dessa crise uma aposta sob incertezas. Embora saibamos que essa crise na Itália facultou a ascensão do totalitarismo sob a alcunha de fascismo, o autor indicou ser possível explorar espaços durante a crise de autoridade, trazendo à tona a importância da unificação orgânica de partidos e bandeiras, que pudessem sintetizar as necessidades da classe trabalhadora. Nas palavras dele essa união "representa a fusão de todo um grupo social sob uma só direção, considerada a única capaz de resolver um problema vital dominante e de afastar um perigo mortal" (GRAMSCI, 2007, p. 60). Porém, alerta ele que, 
[...] Quando a crise não encontra esta solução orgânica, mas sim a do chefe carismático, isto significa que existe um equilíbrio estático (cujos fatores podem ser muito variados, mas entre os quais prevalece a imaturidade das forças progressistas), que nenhum grupo, nem o conservador nem o progressista, dispõe da força necessária para vencer e que até o grupo conservador tem necessidade de um senhor [...] (GRAMSCI, 2007, p. 60).

Nessa direção, entendemos que, em 2018, no Brasil, a eleição da chapa presidencial Bolsonaro e Mourão, ambos militares, foi saturada de elementos de uma crise por hegemonia entre frações da classe dirigente e pela concomitância de uma perda do reconhecimento da representatividade do Partido dos Trabalhadores junto a amplos segmentos sociais, particularmente, os que estavam sendo organizados por igrejas de cariz neopentecostal que migraram o seu apoio para a chapa eleita. Por outro lado, avaliamos que uma suposta união das forças progressistas e de esquerda se deu fragilmente, sem conseguir impedir que o autoritarismo escancarado chegasse ao poder.

Foi nas lacunas deixadas pela crise de autoridade que a retórica da campanha que se assentou fenômeno das fake News e na propagação de discursos conservadores, fazendo conexões ideológicas que aliaram a promessa de combate à corrupção com a intolerante defesa do modelo de família patriarcal. E as respostas a esses supostos compromissos estavam no fortalecimento da guerra às drogas, acompanhado da possibilidade de um governo que colocaria Deus acima de tudo.

\section{A simbiose entre racismo, proibicionismo e guerra às drogas: expressões do autoritarismo neoliberal e seu extermínio}

A ideologia proibicionista tem suas raízes no pensamento puritano norte-americano cunhado no incentivo à propriedade privada, à acumulação e à exploração, ao mesmo tempo em que resiste a qualquer elemento que possa trazer distração, recorrendo-se à ascese (WEBER, 2004). A materialização desse pensamento em legislações leva o Estado a interferir na vida privada potencializando a exploração da força de trabalho, o que se evidencia nos primeiros anos do século XX, quando,

Na América, a racionalização do trabalho e o Proibicionismo estão indubitavelmente conectados: as investigações dos industriais sobre vida intima dos operários, os serviços de inspeção criados por algumas empresas para controlar a moralidade dos operários são necessidades do novo método de trabalho. [...]. (GRAMSCI, 2008, p. 69).

Portanto, a racionalização do trabalho proposta pelo fordismo, contava com uma moralização atenta ao controle dos instintos sexuais e do uso de substâncias psicoativas que pudessem tirar os trabalhadores do foco da produção. Além disso, o Estado burguês também utiliza a instrumentalização da ideologia proibicionista para o controle social de uma forma geral, ampliando o leque de substâncias proibidas de acordo com as singularidades culturais dos grupos a serem atingidos, estabelecendo-se uma dicotomia determinada pelas categorias classe e raça, ditando quem deve ser tratado como traficante, submetido ao controle penal, e quem seria tratado como usuário, dignos de tratamento de saúde. Aqui, se conformou a díade médico-legal que assentou as condições ideológicas e operativas do proibicionismo às drogas (PASSETTI, 1991; LIMA, 2009; BOITEUX, 2006).

Essas particularidades sempre acompanharam a política de drogas exportada dos EUA para o restante do mundo, mas tornam-se severamente evidentes no contexto da crise de capital da década de 1970, quando o Proibicionismo ganha força por meio do estabelecimento da retórica cunhada em uma suposta guerra às drogas, sustentada a partir da construção de inimigos individuais e coletivos (BOITEUX, 2006; VALOIS, 2017). No contexto norte-americano, internamente, os negros são colocados como os principais inimigos (ALEXANDER, 2017). Externamente utiliza-se da guerra às drogas para se fortalecer o ideário da Segurança Nacional, permitindo a imposição de poder dos EUA sobre países em processo de desenvolvimento, em especial na América Latina. Como se pode depreender o proibicionismo às drogas participa de tramas geopolíticas e geoeconômicas ao longo do século XX, conformando outra díade de sustentação (LIMA, 2009; DELMANTO, 2010). 
Nessa correlação de forças, o Brasil sempre esteve alinhado ao proibicionismo norte-americano, reproduzindo legislações e acordos internacionais de forma literal. No entanto, faz essencial destacarmos que o Estado burguês brasileiro se sustenta em bases racistas, no qual o racismo estrutural, integra a organização política, econômica, jurídica da sociedade. Por ser estrutura, é base para o pensamento social coletivo, para as relações inclusive afetivas que desenvolvemos "o racismo fornece o sentido, a lógica e a tecnologia para as formas de desigualdade e violência que moldam a vida social contemporânea" (ALMEIDA, 2018a, p. 16). A particularidade brasileira carrega consigo a constituição de sistemas punitivos essencialmente demarcados pelo racismo, no neodarwinismo e na eugenia (FLAUZINA, 2006; DIWAN, 2018; SCHWARCZ, 2012).

O primeiro Código Criminal do Império, de 1830, criminalizou a vadiagem a mendicância, voltandose especialmente contra negros alforriados e pobres; o Código Criminal republicano, de 1890, por sua vez, acrescenta elementos declaradamente racistas em seu rol de criminalizações, inserindo as categorias criminais a capoeiras e elementos da cultura afro-brasileira (FLAUZINA, 2006). No Brasil dos anos 1930 práticas eugênicas se expandem em diferentes frentes do controle estatal, especialmente no que se refere ao binômio que envolve os poderes médico e legal.

Foi na esteira do pensamento conservador e eugenista da época, que pregava a modernidade do Brasil, a partir de melhoramento da raça e apagamento de tradições africanas, o que Abdias do Nascimento (2016) chamou de genocídio do negro brasileiro. Nesse contexto se recrudescem os ataques às práticas e aos rituais de religiões de matriz africana, as quais sofriam para se manter, concomitante à regulamentação da medicina que se apropriou da preparação de ervas usadas para fins terapêuticos e religiosos, por exemplo. Inclusive, em 1932, o Estado brasileiro se antecipou em cinco anos aos EUA ao estabelecer a primeira legislação proibitiva da cannabis, considerada como fumo de negro (SAAD, 2019; LIMA, 2009).

Em linhas gerais, no contexto do autoritarismo de Vargas, o Estado brasileiro consolida Código Penal de 1940, que ao modernizar as legislações anteriores retira os marcadores racistas explícitos, utilizando-se da cristalização do estigma do negro visto como criminoso em potencial. É no período da Ditadura Militar, pós 1964, que o País adere integralmente à retórica da guerra às drogas, levando o recrudescimento do controle sobre drogas determinadas como proibidas, associando o uso à esquerda, à subversão e à ausência de controle moral, mostrando-se também como parte do ideário da Segurança Nacional brasileira (LIMA, 2009; VALOIS, 2017).

$\mathrm{O}$ que queremos demonstrar com essa regressão temporal é que o proibicionismo às drogas, em suas origens, teve direta relação com mecanismos penais e racistas operados no âmbito do Estado brasileiro para o controle da força de trabalho seja a que diretamente se vinculou ao processo produtivo, seja a que passou a compor o exército de reserva, tão necessário à acumulação capitalista. Nesse circuito, a questão das drogas foi delineada a partir da construção do inimigo - o traficante perigoso - assentado na figura do jovem negro e pobre (ROCHA, 2012, 2013, 2020; FERRUGEM, 2019). Ou seja, a questão do racismo, da seletividade penal e da guerra às drogas são uma constante na história do autoritarismo brasileiro.

A crise mundial do final da década de 1970 trouxe fissuras para a ordem ditatorial brasileira (1964-1985), contexto que fortaleceu os movimentos sociais e sindicais na luta pela retomada da democracia no País. Em concomitância a essa conjuntura brasileira, a saída mundial para crise se assentou na implementação da política econômica neoliberal em meados da década de 1980. As expressões da questão social foram administradas por um menos Estado social em nome do fortalecimento do Estado penal, levando ao estabelecimento sem precedentes do encarceramento em massa (WACQUANT, 2013; GARLAND, 2014; GIORGI, 2013; ALEXANDER, 2017; BORGES, 2018; DAVIS, 2018).

Enquanto Wacquant (2013) aborda a nova ditadura sobre os pobres e Alexander (2017) descreve a nova segregação racial, observamos que no Brasil esses dois elementos se entrecruzam, fortalecendo o racismo estrutural e legitimando ações estatais violentas e genocidas, em nome da guerra às drogas. Assim como em toda a América Latina, os sistemas de segurança vêm operando à margem da legalidade, sem que seja feita censura capaz de limitar esta atuação, e, nesse sentido, a morte é o principal produto (FLAUZINA, 2008). A sinergia entre o racismo, o autoritarismo e o ódio de classes que sustenta este sistema penal, estruturando as práticas sociais e as matrizes discursivas da mídia, promovendo uma retroalimentação da necessidade de uma guerra que tem sido travada nos territórios brasileiros. Nessa perspectiva, a guerra às drogas, reforça no imaginário social a figura do jovem negro como traficante, que deve ser combatido².

O Anuário Brasileiro da Segurança Pública (LIMA; BUENO et al., 2014), aponta que em 2018 das 57.358 mortes violentas intencionais (homicídios), 6.220 foram provocadas por policiais. No entanto, esses índices 
alarmantes da violência letal no Brasil agravaram-se, em 2020, mesmo em tempos de reduzida circulação das pessoas, por conta da pandemia do coronavírus (COVID-19) que assola o mundo, e de maneira particular o Brasil - onde a ofensiva brutal contra o trabalho, a ciência e a pesquisa aceleram o projeto genocida estatal, em coro com um pensamento religioso fundamentalista que fortalece o negacionismo. A racionalidade beligerante derivada, mais uma vez, se materializa no Rio de Janeiro, frente às incursões militarizadas nas favelas, mesmo em período da pandemia. Esta cidade parece ser o front mais danoso da guerra às drogas no País, quando, de forma dissimulada, os agentes do Sistema de Justiça Criminal tratam os assassinados em ações policiais como traficantes. No mês de abril 2020, as intervenções policiais ficaram ainda mais frequentes e, com isso, houve um crescimento da letalidade nas operações em cerca de 60\% em relação a abril de 2019 (REDE DE OBSERVATÓRIOS DA SEGURANÇA, 2020). Esses estarrecedores números de homicídios comprovam que há guerra em tempos de paz sob a justificativa da guerra às drogas.

Refletimos, portanto, que o Estado autoritário e racista é o responsável por essas mortes, primeiro por desregulamentar a questão das drogas a partir dos princípios proibicionistas, fazendo com que essas substâncias sejam mercantilizadas pela ilegalidade e cujos trabalhadores, normalmente, jovens com baixa escolaridade e negros, sejam alvos e autores da violência armada. A guerra às drogas faculta nos aproximar de uma das configurações mais violentas do Estado, oprimindo comunidades inteiras, legalizando prisões seletivas e naturalizando mortes, de pessoas que têm classe e raça determinada. As mortes de crianças negras como Agatha e João Pedro, na cidade do Rio de Janeiro, jamais são fatalidades, tão pouco correspondem a desígnios divinos. Essas mortes são deliberadas, planejadas e executadas em nome de uma guerra estabelecida em supostos tempos de paz. Pretos e pobres jamais descansaram da violência promovida pelo Estado autoritário, porém, o que vemos hoje, é o recrudescimento do projeto genocida necroeconomico, necropolítico, assentado no necropoder (MBEMBE, 2016) e sustentado pelo Neoliberalismo de cunho penal, está mais vivo que nunca.

\section{Fortalecimento neopentecostal no Brasil e crise de autoridade: a presença religiosa na disputa da política de drogas}

Os componentes do autoritarismo político brasileiro se integram ao aprofundamento da ofensiva econômica implementada com as contrarreformas neoliberais, cuja orientação antidemocrática é condição para o sucesso daquela investida (ALMEIDA, 2018b). A Guerra às Drogas oferece um mirante a respeito da violência institucional que reproduz o racismo e, de forma concomitante, com o crescimento do neopentecostalismo, faz convergir a combinação de um tipo de organização armada do mercado das drogas ilícitas com uma adesão religiosa do tipo fundamentalista. No Rio de Janeiro, a violência contra espaços e lideranças religiosas de matriz afro em algumas favelas e bairros da periferia vem sendo operada por jovens que seguram fuzis e a bíblia.

Umbanda, candomblé e suas variantes regionais têm motivos palpáveis para temer a expansão do neopentecostalismo, visto que o objetivo da guerra espiritual é, além de converter os adeptos das religiões adversárias, fechar centros espíritas, tendas de umbanda e terreiros de candomblé existentes ao redor dos templos crentes. Isso decorre de seus propósitos expansionistas e de suas concepções doutrinárias, que superdimensionam a ação e o poder malignos do Diabo no mundo, exacerbam o combate aos demônios e hipertrofiam a necessidade de libertação ritual. (MARIANO, 2014, p. 117).

Tal perseguição no final da década de 1990, quando foi escrita a primeira edição do livro do sociólogo das religiões Ricardo Mariano (2014), não era acompanhada de grupos armados partícipes da economia do varejo das drogas. Como se leu, o preconceito, a discriminação e o encalce se dava pela proximidade física aos templos neopentecostais (Assembleia de Deus, Igreja Universal do Reino de Deus, dentre outras). Conquanto, o que já assistimos em cidades como o Rio de Janeiro são territórios purificados por milícias religiosas que exigem a interrupção do uso do atabaque e a retirada de todos os símbolos das religiões afros, ao materializar a intolerância religiosa beligerante com a combinação de que a "lei do tráfico é a lei de Deus" (MAXX, 2020). Esse encontro entre traficrentes e chefes locais do tráfico de drogas, também, pastores, ainda merece estudos, segundo Maxx (2020), pois não se sabe as motivações "[...] se é preconceito ou pura disputa de território e fiéis (e de seus bolsos e votos)" (MAXX, 2020, s. p.), ou se inclusive subjaz, como a própria economia do proibicionismo às drogas, lavagem de dinheiro. 
É importante observar que o crescimento dos evangélicos no Brasil acompanhou a curva de declínio dos católicos na América Latina a partir dos anos de 1970. Segundo o Relatório "Religião na América Latina Mudança Generalizada em uma Região Historicamente Católica” (BELL; SAHGAL; RITCHEY et al., 2014), até aquela década tínhamos $92 \%$ de brasileiros referindo ser católicos, declinando para $61 \%$ em 2013. A partir deste período recente, um em cada cinco brasileiros referiram ser ex-católicos, migrando preferencialmente para as igrejas protestantes ${ }^{3}$ e outra parte menor não se filiando a qualquer religião.

As motivações dos latino-americanos para saída da Igreja Católica merecem a nossa atenção, na medida em que referem buscar uma conexão individual com Deus; identificar-se com o estilo de êxtase religioso promovido nos cultos neopentecostais; querer maior ênfase numa moralidade que os oriente sobre casamento, família, drogas, aborto etc.; valorizar uma igreja que ajuda os membros e oferece assistência aos pobres, aproximando-os de Cristo; e buscar um futuro financeiro melhor.

Como se pode observar, essa relação de interesses dos protestantes convergiu com a expansão da nova razão do mundo, o neoliberalismo e sua feição neoconservadora (DARDOT; LAVAL; 2016), seja pelo conteúdo seja pela concomitância do mesmo período histórico catalisador, a década de 1970. No Brasil, Mariano (2014) registrou o crescimento das igrejas protestantes de cariz pentecostal, cujo culto evoca o que nomeiam de dons do Espírito Santo, tais como cura divina, falar em línguas e receber revelações diretas de Deus, a partir de 1980. Eles já se fizeram presentes na Constituinte e junto com os políticos católicos incidiram sobre temas como a proibição ao aborto.

Justamente, segmentos católicos e protestantes conseguiram organizar forças políticas para requisitar recursos públicos para suas nomeadas comunidades terapêuticas, totalizando $82 \%$ de todas as existentes no País, segundo levantamento do Instituto de Pesquisa Econômica Aplicada (2017). Como dito antes, temos uma disputa por autoridade sobre a concepção de droga e sobre a direção desta política pública, dissociando-a do universalismo, da formação científica das profissões e da laicidade subjacente à defesa de um sistema de saúde público.

Conquanto, esses componentes autoritários, na aparência particulares da política de drogas brasileira, nos parecem ser tendências mais gerais e complexas de uma natureza do Estado moderno à serviço da classe burguesa e de uma racionalidade neoliberal contemporânea que atinge todas as esferas das relações sociais. Para Brown (2019, p. 18), porém, ao revisitar o pensamento dos fundadores do neoliberalismo - Friedrich Hayek e Milton Friedman -, a autora afirmou que "[...] o entusiasmo popular com os regimes autocráticos, nacionalistas e em alguns casos neofascistas [...] afasta-se tão radicalmente dos ideais neoliberais quanto os regimes comunistas estatais repressivos afastavam-se de Marx". O que parece ser um paradoxo entre origens e processo histórico efetivo apenas faculta a autora cotejar o alcance e a ruína provocada pelo ataque neoliberal a qualquer projeto emancipatório.

Compreender as raízes e as forças da situação atual requer avaliar a cultura política e a produção subjetiva neoliberais, e não somente as condições econômicas e os racismos persistentes que a geraram. Significa avaliar que a ascensão das formações políticas nacionalistas autoritárias brancas se deve à raiva instrumentalizada dos indivíduos abandonados economicamente e ressentidos racialmente, mas também delineada por mais de três décadas de assaltos neoliberais à democracia, à igualdade e à sociedade. O sofrimento econômico e o rancor racial das classes trabalhadora e média brancas, longe de se distinguir desses assaltos, adquire voz e forma a partir deles. Esses ataques também abastecem [...] a ambição nacionalista cristã de (re) conquistar o Ocidente. Eles também se misturam com um niilismo intenso que se manifesta como perda da fé na verdade, na facticidade e em valores fundamentais (BROWN, 2019, p. 17).

Nessa direção, uma construção que é cotidianamente realizada pelo conservadorismo que liga a religião à política no Brasil, carregando consigo um movimento que tenta impor inúmeros valores religiosos em forma de lei, os quais, se situam na esfera da violação de direitos humanos da maioria. Ainda que os instrumentos para a criminalização às religiões de matriz africana tenham se diluído ao longo dos anos, o racismo estrutural cria as condições para que o ideário criminalizador persista. Senão por força de uma lei proibitiva, por ataques sistemáticos, e como vimos, crescentes a seus rituais, o sagrado de seus espaços e suas doutrinas ancestrais, que buscam também restituir às pessoas, sobretudo negras, o que a violência do Estado Penal retira. Um processo reiterado de desumanização do corpo negro descartável, como nos sinaliza Ângela Davis (2018, p. 85): “Ao 
longo de grande parte da história, a própria categoria de 'ser humano' não abarcou as pessoas negras e de minorias étnicas. Seu caráter abstrato era formado pela cor branca e pelo gênero masculino”.

Assim, atribui-se um signo negativo, há algo que se desconhece e deseja-se extirpar. Por carregar elementos que remetem à cultura africana, em uma demonstração de racismo religioso, como uma das manifestações de um racismo estruturante. Atribui sentido, assim, as abordagens dos agentes de segurança, não só pelas crenças que os atravessam, mas também pela autorização de morte que o estado permanente de guerra parece conferir, e para que não haja dúvida, governantes emitem pronunciamentos para reiterar esta autorização, fazendo com que as ações executadas sejam sempre preventivas, justificando uma série de infrações e crimes, que parecem suspender as legislações vigentes. No território invadido sob a insígnia de operação policial, não há vidas a serem protegidas, moradias a serem respeitadas, não há direito de ir e vir, nem direito de as crianças frequentarem as aulas.

\section{Considerações Finais}

Neste artigo buscamos compreender o acirramento do autoritarismo no Brasil, a partir de múltiplas dimensões, dentre elas destacamos o Sistema Penal, que baliza a criminalização em larga escala, de jovens negros, sob a alcunha do tráfico de drogas tornadas ilícitas e o racismo religioso manifesto na intolerância a religiões de matriz afro-brasileira. Controle que incide sobre o sistemático uso da força do Estado, supostamente face à proibição das drogas tornadas ilícitas, a partir de uma intensificação da política de guerra às drogas. Elementos que carregam o racismo como estruturante e afetam diretamente a classe trabalhadora, mais precarizada, tanto os que trabalham no comércio ilegal das drogas quanto os que sem ter posto neste mercado sofrem as consequências de residir num território com incursões militarizadas cotidianas. Esta resposta em período de neoliberalismo e de neoconservadorismo é seletiva e requisita apreender dois componentes do racismo estrutural: o racismo institucional e o religioso que se atualizam na política de drogas.

Situamos essas reflexões no debate acerca da crise de autoridade, que pode culminar em dois caminhos, o primeiro, como reflete Gramsci, poderia se materializar a partir da união das lutas da classe trabalhadora visando à reconstrução de caminhos anteriormente impostos. Ou, como segundo caminho, está o fortalecimento do Estado reacionário, que se assenta no conservadorismo. Observamos que a destituição da Presidenta Dilma Rousseff indicou uma crise geral de autoridade, fortaleceu a ascensão neopentecostal na organização das massas populares no Brasil a favor de um projeto necroeconômico e necropolítico abertamente antidemocrático. No interior do Estado neoliberal de cunho penal, o conservadorismo, racismo e ódio de classe recrudescem mecanismos de controle justificado pela guerra às drogas, incidindo sobre os corpos e qualquer vestígio de vida de negros e pobres, de sua cultura, religião ou ancestralidade.

\section{Referências}

ALEXANDER, M. A nova segregação: racismo e encarceramento em massa. São Paulo: Boitempo, 2017.

ALMEIDA, S. O Que É Racismo Estrutural? Belo Horizonte: Letramento, 2018a.

ALMEIDA, S. Neoconservadorismo e liberalismo. In: GALLEGO, Esther Solano (Org.). O ódio como política [recurso eletrônico]: a reinvenção das direitas no Brasil. São Paulo, Boitempo, 2018b, pp. 25-31.

BARATTA, A.; BISSOLI FILHO, F. B. Princípios do Direito Penal Mínimo. Florianópolis: Habitus, 2019.

BELL, J.; SAHGAL, N.; RITCHEY, K. et al. Religião na América Latina: Mudança Generalizada em uma Região Historicamente Católica. Pew Research Center, Washington DC 13 nov. 2014. Disponível em: https://www.pewresearch.org/wp-content/uploads/ sites/7/2014/11/PEW-RESEARCH-CENTER-Religion-in-Latin-America-Portuguese-Overview-for-publication-11-13.pdf. Acesso em: 30 maio 2020 .

BOITEUX, L. Controle penal sobre as drogas ilícitas: o impacto do proibicionismo no sistema penal e na sociedade. 2006. Tese (Doutorado em Direito) - Departamento de Direito Penal, Medicina Legal e Criminologia da Faculdade de Direito. Universidade de São Paulo São Paulo, 2006.

BORGES, J. O que é encarceramento em massa?. Belo Horizonte-MG: Letramento: Justificando, 2018

BROWN, W. Nas ruínas do neoliberalismo: a ascensão da política antidemocrática no ocidente. São Paulo: Ed. Filosófica Politeia, 2019. 
CUNHA, M. do N. Como se formou a hegemonia pentecostal no Brasil. Vermelho, 2019. Disponível em: https://vermelho.org. br/2019/12/04/magali-cunha-como-se-formou-a-hegemonia-pentecostal-no-brasil/. Acesso em: 03 jan 2020.

DARDOT, P.; LAVAL, C. A nova razão do mundo: ensaio sobre a sociedade neoliberal. São Paulo: Boitempo, 2016.

DAVIS, A. A liberdade é uma luta constante. São Paulo: Boitempo, 2018.

DELMANTO, J. Imperialismo e proibicionismo: raízes e interesses da proibição das drogas e da suposta guerra ao tráfico. Núcleo de Estudos Interdisciplinares sobre psicoativos, 2010. Disponível em: https://neip.info/novo/wp-content/uploads/2015/04/imperialismoe-proibicionismo-jlio-delmanto.pdf. Acesso em: 15 mar. 2012.

DIWAN, P. Raça pura: uma história da eugenia no Brasil e no mundo. São Paulo: Contexto, 2018

FEFFERMAN, M. Vidas Arriscadas: o cotidiano dos jovens trabalhadores do tráfico. Petrópolis: Vozes, 2006.

FERRUGEM, D. A guerra às drogas e a manutenção da hierarquia racial. Belo Horizonte: Letramento, 2019.

FLAUZINA, A. L. P. Corpo negro caído no chão: o sistema penal e o projeto genocida do Estado brasileiro. Rio de Janeiro: Contraponto, 2008.

GARLAND, D. A cultura do controle: crime e ordem social na sociedade contemporânea. Rio de Janeiro: Revan, 2014.

GIORGI, A. De. A miséria governada através do sistema penal. Rio de Janeiro: Revan, 2013.

GRAMSCI, A. Americanismo e Fordismo. São Paulo: Hedra, 2008.

GRAMSCI, A. Cadernos do Cárcere, volume 1. Rio de Janeiro: Civilização Brasileira, 1999.

GRAMSCI, A. Cadernos do cárcere, volume 3. Rio de Janeiro: Civilização Brasileira, 2007.

HALL, S. Da diáspora: identidades e mediações culturais. Belo Horizonte: Ed. da UFMG, 2003

INSTITUTO DE PESQUISA ECONÔMICA APLICADA. Nota Técnica nº 21. Perfil das Comunidades Terapêuticas Brasileiras. Brasília: Diretoria de Estudos e Políticas do Estado, das Instituições e da Democracia, IPEA, março de 2017.

LIMA, R. S.; BUENO S. et al. Anuário Brasileiro de Segurança Pública 2014. São Paulo: Fórum Brasileiro de Segurança Pública; 2014. v.8.

LIMA, R. de C. C. Uma história das drogas e do seu proibicionismo transnacional: relações Brasil-Estados Unidos e os organismos internacionais. 2009. 365 f. Tese (Doutorado em Serviço Social) - Programa de Pós-Graduação em Serviço Social da Universidade Federal do Rio de Janeiro, Rio de Janeiro, 2009.

MARIANO, R. Neopentecostais: sociologia do novo pentecostalismo no Brasil. São Paulo: Loyola, 2014.

MARX, K.; ENGELS, F. A ideologia alemã. São Paulo: Boitempo, 2016.

MBEMBE, A. Necropolítica: biopoder soberania, estado de exceção, política da morte. Arte \& Ensaios. Revista do PPGAV/EBA/ UFRJ, n. 32, dezembro 2016

MAXX, M. Nação de Jesus: Fuzis ungidos e grafite gospel em muros da comunidade. UOL Tab, 27 maio 2020. Não paginado. Disponível em: https://tab.uol.com.br/edicao/nacao-de-jesus/index.htm. Acesso em: 30 maio 2020.

NASCIMENTO, A. O genocídio do Negro Brasileiro: processo de um racismo mascarado. São Paulo: Perspectivas, 2016.

PASSETTI, E. Das fumeries ao narcotráfico. São Paulo: EDUC, 1991.

REDE DE OBSERVATÓRIOS DA SEGURANÇA. Operações policiais em meio a pandemia. Disponível em: www.observatorioseguranca. com.br. Acesso em: 30 jun. 2020.

ROCHA, A. P. Proibicionismo e a criminalização de adolescentes pobres por tráfico de drogas. Revista Serviço Social e Sociedade, n. 115, p. 561-580, 2013.

ROCHA, A. P. Trajetórias de adolescentes apreendidos como "mulas" do transporte de drogas na região da fronteira (Paraná) BrasilParaguai: exploração de força de trabalho e criminalização da pobreza. 2012. 396 f. Tese (Doutorado em Serviço Social) - Faculdade de Ciências Humanas e Sociais, Universidade Estadual Paulista "Júlio de Mesquita Filho", Franca/SP, 2012.

ROCHA, A. P. O juvenicídio brasileiro: racismo, guerra às drogas e prisões. Londrina/PR: EDUEL, 2020 (no prelo)

RODRIGUES, T. M. S. Política e drogas nas Américas. São Paulo: EDUC; FAPESP, 2004.

SAAD, L. Fumo de Negro. Salvador: EDUFBA, 2019.

SCHWARCZ, L. M. Sobre o autoritarismo brasileiro. $1^{\text {a }}$. ed. São Paulo: Companhia da Letras, 2019

SCHWARCZ, L. M. Nem preto nem branco: muito pelo contrário: cor e raça na sociedade brasileira. 1ª São Paulo: Claro Enigma, 2012. VALOIS, L. C. O Direito Penal da Guerra às Drogas. Belo Horizonte: D’plácido, 2017.

VASCONCELOS, E.; CAVALCANTE, R. Religiões e o paradoxo apoio social: intolerância, implicações na política de drogas e comunidades terapêuticas. São Paulo: Hucitec, 2019.

VIEIRA, H. Fundamentalismo e extremismo não esgotam experiência do sagrado nas religiões. In: GALLEGO, Esther Solano (Org.). O ódio como política [recurso eletrônico]: a reinvenção das direitas no Brasil. São Paulo, Boitempo, 2018, pp. 95-101.

WACQUANT, L. Punir os Pobres: a nova gestão da miséria nos Estados Unidos. Tradução de Sérgio Lamarão. Rio de Janeiro: Revan, 2003, $3^{\text {a }}$. edição, revista e ampliada, agosto de 2007. $1^{\text {a }}$. reimpressão, março de 2013. Rio de Janeiro: Revan, 2013.

WEBER, M. A ética protestante e o "espírito" do capitalismo. São Paulo: Companhia das Letras, 2004.

ZAFFARONI, E. O inimigo do Direito Penal. Rio de Janeiro: Revan, 2014. 


\title{
Notas
}

1 Hall (2003, p. 308) reconhece a contribuição gramsciana para o estudo do racismo por considerá-lo como um fenômeno histórico, que sofre determinantes sociais, políticos, culturais.

2 E, no paralelo, o tráfico de drogas, também serve a esse genocídio à medida que, no bojo de suas lutas internas pela condução dos mercados de drogas, provoca muitas mortes. As relações de trabalho acontecem abaixo da pressão e do medo da morte, quando o jovem que está na ponta do tráfico de drogas é visto como um problema, ele é demitido da vida (FEFFERMAN, 2006; ROCHA, 2012, 2013)

3 Leia-se protestantes históricas, como as igrejas Batistas, Adventistas do Sétimo Dia, Metodistas, Luteranos ou Presbiterianos; igrejas pentecostais, como as Assembleias de Deus, Universal do Reino de Deus, Igreja Pentecostal de Deus ou Igreja do Evangelho Quadrangular e outras igrejas protestantes; sendo as pentecostais as que congregam 50\% dos protestantes na América Latina (BELL; SAHGAL; RITCHEY et al., 2014).

\author{
Andréa Pires Rocha \\ drea_rocha@yahoo.com.br \\ Doutora em Serviço Social pela Universidade Estadual Paulista (UNESP) \\ Professora Adjunta da Universidade Estadual de Londrina (UEL)
}

\section{UEL}

Rodovia Celso Garcia Cid, PR 445 Km 380, Campus Universitário

Londrina - PR - Brasil

CEP: Postal 10.011 / CEP 86.057-970

\section{Rita de Cássia Cavalcante Lima}

ritacavalcante69@gmail.com

Doutora em Serviço Social pela Universidade Federal do Rio de Janeiro (UFRJ)

Professora Associada da Escola de Serviço Social da Universidade Federal do Rio de Janeiro (UFRJ)

\section{ESS/UFRJ}

Av. Pasteur, 250, fundos, Urca

Rio de Janeiro - RJ - Brasil

CEP: 22.290-902

\section{Daniela Ferrugem}

danielaferrugem@yahoo.com.br

Mestra em Serviço Social Pontifícia Universidade Católica do Rio Grande do Sul (PUC/RS)

Assistente Social do Instituto de Psicologia da Universidade Federal do Rio Grande do Sul (UFRGS)

\section{UFRGS}

Ramiro Barcelos, 2600. Bairro Santa Cecilia. Campus Saúde

Porto Alegre - RS - Brasil

CEP: 90035-00

\section{Agradecimentos}

Não se aplica.

\section{Agência financiadora}

Daniela Ferrugem desenvolve o doutorado com bolsa CAPES.

\section{Contribuições das autoras}

$\mathrm{O}$ ensaio foi escrito em coautoria e trata de temática de estudo, ensino e pesquisa das autoras, que pertencem a rede de pesquisa que tem como temática a questão das drogas e o Serviço Social. Cada autora tratou das discussões particulares 
de suas pesquisas, portanto, a escrita conjunta permitiu que as conexões fossem estabelecidas dialeticamente.

Aprovação por Comitê de Ética e consentimento para

participação

Não se aplica.

\section{Consentimento para publicação}

Cometimento das autoras.

Conflito de interesses

Não há conflito de interesses. 